\title{
TIAMINA COMO ATENUADOR DO ESTRESSE SALINO EM SEMENTES DE
}

\section{ARROZ}

Eliene Almeida Paraizo ${ }^{1 *}$, Andréia Márcia Santos de Souza David ${ }^{2}$, Edileuza dos Reis Souza Conceição ${ }^{3}$, Rafael Rogério Pereira da Silva ${ }^{3}$, Cleisson Dener da Silva ${ }^{3}$, Danúbia Aparecida Costa Nobre ${ }^{4}$

\footnotetext{
${ }^{1}$ Doutoranda em Produção Vegetal no Semiárido, Universidade Estadual de Montes Claros (Unimontes), Janaúba, MG. *E-mail do autor correspondente: elieneparaizolik@ hotmail.com

${ }^{2}$ Docente do curso de Agronomia, Universidade Estadual de Montes Claros (Unimontes), Janaúba, MG.

${ }^{3}$ Mestre em Produção Vegetal no Semiárido, Universidade Estadual de Montes Claros (Unimontes), Janaúba, MG.

${ }^{4}$ Docente do curso de Agronomia, Universidade Federal dos Vales do Jequitinhonha e Mucuri (UFVJM), Campus JK, Diamantina, MG.
}

Recebido: 14/05/2020; Aceito: 08/09/2021

RESUMO: A tiamina é uma vitamina com atividade antioxidante que tem sido relatada como capaz de amenizar os efeitos causados por estresse biótico e abiótico. Neste trabalho, estudos foram realizados para avaliar o efeito da aplicação exógena do antioxidante tiamina em sementes de arroz sob condições de estresse salino. Foi utilizado o delineamento inteiramente casualizado, com seis tratamentos que consistiram nas concentrações de tiamina $(0,30,60,90$, 120 e $150 \mathrm{mg} \mathrm{L}^{-1}$ ), com quatro repetições. As sementes de arroz imersas em soluções de tiamina foram semeadas em papel germitest ${ }^{\circledR}$, umedecido com solução de cloreto de sódio (-0,6 MPa) em volume equivalente a 2,5 vezes o peso do papel seco. A seguir, foram analisadas as variáveis fisiológicas: germinação, primeira contagem de germinação, índice de velocidade de germinação, comprimento de plântulas e massa seca de plântulas. Os dados foram submetidos à análise de variância e regressão a $5 \%$ de probabilidade. A partir dos resultados obtidos, constatou-se que a aplicação da tiamina estimulou a germinação e demonstrou melhores respostas no desenvolvimento inicial de plântulas de arroz em condições de estresse salino quando comparadas ao tratamento controle. A medida que se elevou a concentração de tiamina, houve incremento em todas as características avaliadas cuja concentração de $150 \mathrm{mg} \mathrm{L} \mathrm{L}^{-1}$ possibilitou máximos resultados de germinação $(71,14 \%)$, primeira contagem de germinação $(64,85 \%)$, índice de velocidade de germinação $(16,20)$ e comprimento de plântulas $(8,2 \mathrm{~cm})$.

Palavras-chave: Germinação. Vigor. Antioxidante. Salinidade. Oryza sativa.

\section{THIAMINE AS A SALT STRESS ATTENUATOR IN RICE SEEDS}

\begin{abstract}
Thiamine is a vitamin with antioxidant activity that has been reported to mitigate the effects caused by biotic and abiotic stress. In this work, studies were carried out to evaluate the effect of exogenous application of the antioxidant thiamine in rice seeds under conditions of salt stress. A completely randomized design was used, with six treatments consisting of thiamine concentrations $(0,30,60,90,120$ and $150 \mathrm{mg} \mathrm{L}-1)$, with four replications. Rice seeds immersed in thiamine solutions were sown on germitest ${ }^{\circledR}$ paper, moistened with sodium chloride solution (-0.6 MPa) in a volume equivalent to 2.5 times the weight of the dry paper.
\end{abstract}


Then, physiological variables were analyzed: germination, first germination count, germination speed index, seedling length and seedling dry mass. Data were subjected to analysis of variance and regression at $5 \%$ probability. From the results obtained, it was found that the application of thiamine stimulated germination and showed better responses in the initial development of rice seedlings under conditions of salt stress when compared to the control treatment. As the concentration of thiamine increased, there was an increase in all characteristics evaluated whose concentration of $150 \mathrm{mg} \mathrm{L}-1$ allowed maximum germination results (71.14\%), first germination count $(64.85 \%)$, index of germination speed $(16.20)$ and seedling length $(8.2 \mathrm{~cm})$.

Key words: Germination. Vigor. Antioxidant. Salinity. Oryza sativa.

\section{INTRODUÇÃO}

Na cultura do arroz (Oryza sativa L.), com o decorrer do tempo, a irrigação por inundação pode conduzir a salinização de solos que não possuem drenagem adequada, tornando impraticável a continuidade do cultivo em certas áreas (LIMA et al., 2004). Logo, a presença de sais no solo e na água de irrigação constitui fator limitante para o cultivo do arroz, principalmente nos estágios iniciais do desenvolvimento (BENITEZ et al., 2011).

Considerando esse contexto, a salinidade é um dos mais importantes fatores de estresse abiótico que afeta diversos aspectos fisiológicos e bioquímicos durante o processo germinativo das sementes e emergência de plântulas, comprometendo o estabelecimento da cultura. $\mathrm{O}$ excesso de sais solúveis reduz o potencial hídrico do solo, induzindo menor capacidade de absorção de água pelas sementes (LARRÉ et al., 2011). Desse modo, é gerado déficit hídrico e desequilíbrio iônico nas células, resultando em toxicidade e estresse osmótico (KHAN; PANDA, 2008).

$\mathrm{Na}$ tentativa de atenuar os estresses bióticos e abióticos e seus efeitos deletérios, diferentes produtos têm sido estudados, e entre eles, encontram-se as vitaminas. De acordo com Goyer (2010), entre as mitigadoras de estresse, tem se constatado o uso potencial da vitamina B1(tiamina).

Estudos demonstram que a aplicação de tiamina induz tolerância ao estresse hídrico e salino em diversas espécies vegetais, com ganhos para as características biométricas e produtivas de plantas de arroz (VENDRUSCOLO et al., 2020), aumento de vigor e estímulo da emergência em plântulas de feijão (VENDRUSCOLO et al., 2018), incrementos no crescimento de plântulas de trigo (EZZAT, 2021), além de aliviar o estresse oxidativo durante diferentes condições de estresse abiótico em Arabidopsis (TUNC-OZDEMIR et al., 2009). Diante do exposto, sugere-se que a aplicação exógena de tiamina impõe efeitos favoráveis no desenvolvimento e crescimento de planta sob estresses (KAYA et al., 2015).

O crescimento vegetal induzido por aplicação de tiamina, parece está associado a ação antioxidante (GOYER, 2010), formação de compostos secundários em vias metabólicas (TUNC-OZDEMIR et al., 2009), mecanismos de defesa contra agentes patogênicos (BOUBAKRI et al., 2012) e acúmulo de açúcar solúvel, que pode proteger a integridade das 
membranas celulares (SAYED; GADALLAH, 2002), o que controla e favorece o processo de absorção de água pelas sementes, bem como, o seu desenvolvimento.

Face às considerações acerca do potencial da tiamina na redução dos efeitos danosos de estresses abióticos, objetivou-se com o presente estudo avaliar o efeito da aplicação exógena da tiamina em sementes de arroz sob condições de estresse salino.

\section{MATERIAL E MÉTODOS}

O experimento foi conduzido no Laboratório de Análise de Sementes da Universidade Estadual de Montes Claros (Unimontes), campus Janaúba, MG. Foram utilizadas sementes de arroz, cultivar Rubelita, produzidas no Norte de Minas Gerais.

Inicialmente foi determinado o teor de água das sementes, a $105 \pm 3{ }^{\circ} \mathrm{C}$, durante 24 horas, com quatro repetições de 50 sementes, sendo os resultados expressos em porcentagem (BRASIL, 2009).

O delineamento experimental utilizado foi o inteiramente casualizado, composto por seis concentrações de tiamina $(99,4 \%$ i. a.), que consistiram nos tratamentos, com quatro repetições de 50 sementes. Amostras de 100 gramas de sementes foram tratadas nas concentrações de 0 (controle, utilizando-se água destilada), 30, 60, 90, 120 e $150 \mathrm{mg} \mathrm{L}^{-1}$, do antioxidante que foi dissolvido em $250 \mathrm{~mL}$ de água destilada. Sob condições de total embebição, as sementes permaneceram nas soluções durante 24 horas e, em seguida, foram secas em condições ambientais de laboratório, para a retirada da água superficial, até o início das análises.

Para o teste de germinação, as sementes foram semeadas em rolo de papel germitest ${ }^{\circledR}$, umedecido com solução de cloreto de sódio com potencial osmótico de -0,6 MPa, em volume equivalente a 2,5 vezes o peso do papel seco. Os rolos foram mantidos em germinador regulado à temperatura constante de $25{ }^{\circ} \mathrm{C}$ e os resultados foram obtidos pelo número de plântulas normais (estruturas essenciais completas, desenvolvidas, proporcionais e sadias), determinado por ocasião do quinto e décimo quarto dia após a montagem do teste, com os resultados expressos em porcentagem (BRASIL, 2009).

A primeira contagem de germinação foi realizada simultaneamente ao teste de germinação, registrando-se a porcentagem de plântulas normais obtidas no quinto dia após a semeadura (BRASIL, 2009).

O índice de velocidade de germinação (IVG) foi determinado a partir de contagens diárias do número de sementes que apresentaram emissão de radícula até aos 14 dias após a semeadura, conforme equação sugerida por Maguire (1962):

$$
\mathrm{IVG}=\mathrm{N} 1 / \mathrm{D} 1+\mathrm{N} 2 / \mathrm{D} 2+\ldots+\mathrm{Nn} / \mathrm{Dn}
$$

Onde: IVG = índice de velocidade de germinação; N1, N2 ... Nn = número de sementes germinadas na primeira contagem, segunda contagem ... n-ésima contagem; D1, D2 ... Dn = número de dias na primeira contagem, segunda contagem ... n-ésima contagem, respectivamente. 
O comprimento de plântulas foi realizado no décimo quarto dia após a semeadura, utilizando-se 10 plântulas de cada repetição, com auxílio de uma régua milimétrica, e os resultados foram expressos em centímetros.

Para a massa seca de plântulas foram utilizadas as plântulas normais resultantes do teste de germinação que foram acondicionadas em sacos de papel, identificados e levados para secar em estufa com circulação de ar forçada, a $65^{\circ} \mathrm{C}$ até atingir peso constante ( 72 horas). Decorrido esse período, as amostras foram pesadas em balança analítica com precisão de 0,001 g, com resultados expressos em mg plântula ${ }^{-1}$.

Os dados foram submetidos à análise de regressão, utilizando-se o programa estatístico Sisvar (FERREIRA, 2011). Foram selecionadas as equações de regressão que apresentaram maior coeficiente de determinação $\left(\mathrm{R}^{2}\right)$, estimativas dos parâmetros significativas em nível de $5 \%$ de significância pelo teste " $\mathrm{t}$ ” e comportamento com explicação biológica.

\section{RESULTADOS E DISCUSSÃO}

A determinação do teor de água das sementes, como procedimento inicial, indicou valores médios de $10,4 \%$ de umidade, considerado relativamente baixo, sugerindo não haver interferência nos resultados obtidos das demais análises. Este fato é importante, considerandose que a longevidade das sementes está diretamente ligada ao teor de água, uma vez que esta interfere diretamente nos processos fisiológicos, com redução da qualidade da semente, chegando a afetar diretamente o vigor e até o poder germinativo (MARCOS FILHO, 2015).

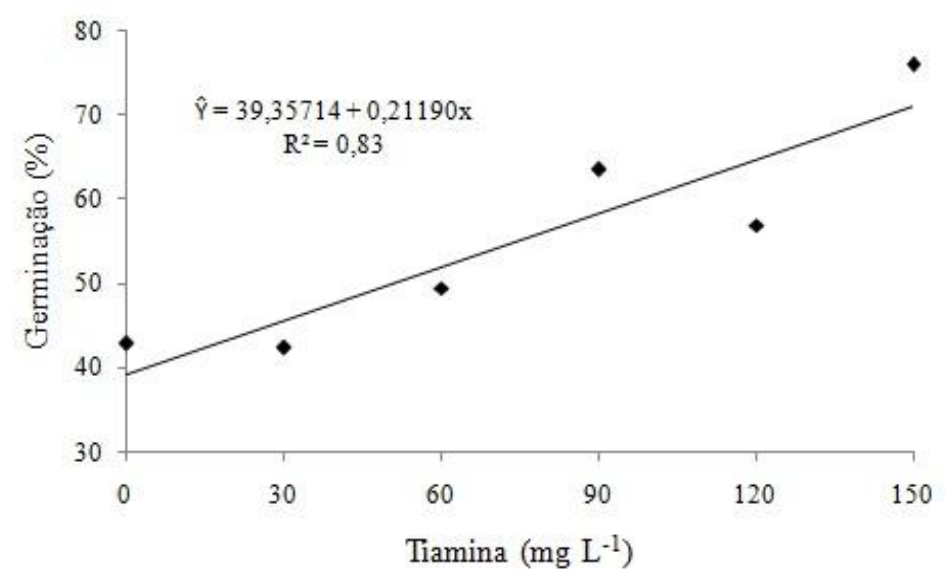

Figura 1. Germinação de sementes de arroz submetidas ao estresse salino em função de concentrações de tiamina. Germination of rice seeds subjected to saline stress due to thiamine concentrations.

Fonte: Autoria própria. Own authorship.

De acordo com o resultado das análises, a germinação de sementes foi influenciada pela aplicação das concentrações de tiamina, com ajuste ao modelo linear crescente, no qual observaram-se incrementos na porcentagem de germinação proporcionais ao aumento das concentrações (Figura 1). O máximo percentual $(71,14 \%)$ foi obtido na concentração de 150 $\mathrm{mg} \mathrm{L}^{-1}$ de tiamina, demonstrando o efeito atenuador da tiamina no processo de germinação das sementes de arroz sob condições de estresse salino. Ademais, vale destacar que apesar da 
condição de estresse salino, com a utilização da máxima concentração estudada, as sementes atingiram o percentual mínimo de germinação exigido pelos padrões nacionais para semente básica de arroz que é de 70\% (BRASIL, 2013).

A aplicação de tiamina induz a tolerância ao estresse oxidativo em plantas (TUNCOZDEMIR et al., 2009; TUNA et al., 2013). Nesse sentido, o efeito atenuante da tiamina na germinação de sementes de arroz pode ser atribuído ao seu papel como coenzima em várias vias metabólicas, como o metabolismo do açúcar e de proteínas (GOYER, 2010).

Desse modo, sugere-se que a melhoria na germinação de sementes nas maiores concentrações possa ter sido resultante dos efeitos protetores impostos pela tiamina no metabolismo celular de carbono e nitrogênio contra o estresse oxidativo induzido por sal em sementes durante o processo germinativo (KAYA et al., 2015).

Os resultados encontrados no presente estudo corroboram com os obtidos por Kaya et al. (2015). Os autores verificaram que a aplicação de tiamina em sementes de milho aumentou a germinação e registraram concentrações mais eficazes para atenuar os efeitos adversos da salinidade de 100 e $125 \mathrm{mg} \mathrm{L}^{-1}$. Neumann, Azaizeh e Marschner (1996) também observaram aumento da taxa de germinação de sementes de feijão tratadas com tiamina e expostas a lesão por imersão e reportaram melhores respostas na concentração de $3 \mathrm{mM}$, aplicada durante as primeiras 24 horas de embebição.

A primeira contagem de germinação ajustou-se a um modelo de regressão de comportamento quadrático (Figura 2), com incremento nos valores proporcionais ao aumento das concentrações de tiamina, onde a maior porcentagem de germinação na primeira contagem $(64,85)$ foi obtida na concentração de $150 \mathrm{mg} \mathrm{L}^{-1}$. A primeira contagem de germinação é um teste de vigor simples e assume como pressuposto, de que as sementes mais vigorosas germinam primeiro. Nesse sentido, os resultados apontam que as sementes tratadas com tiamina foram capazes de germinar mais rapidamente quando em comparação ao controle (sem tiamina), evidenciando, assim, o seu efeito benéfico em atenuar os efeitos do estresse salino no vigor das sementes.

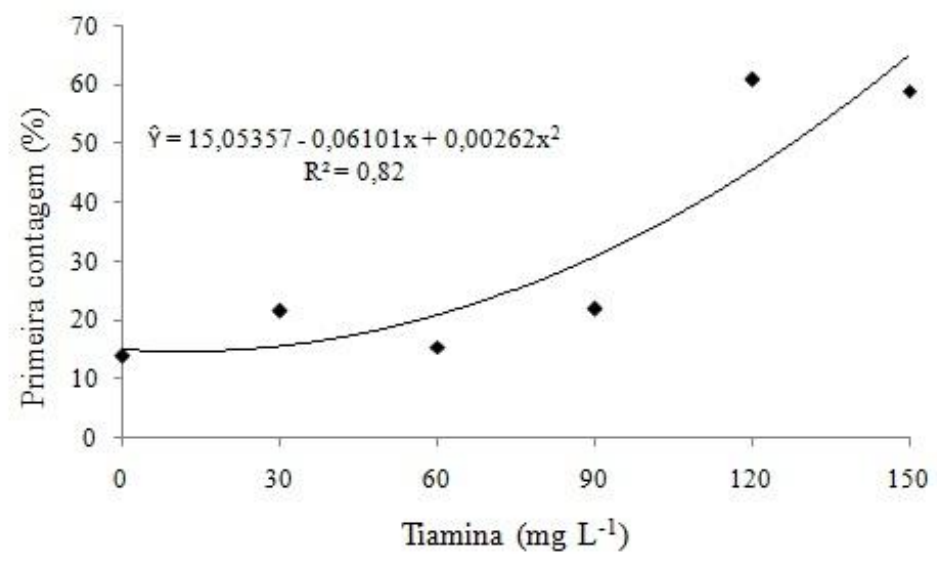

Figura 2. Primeira contagem de germinação de sementes de arroz submetidas ao estresse salino em função de concentrações de tiamina. First germination count of rice seeds subjected to saline stress as a function of thiamine concentrations.

Fonte: Autoria própria. Own authorship. 
É provável que o uso de antioxidantes solúveis em água como a tiamina possa ter importante função protetora durante o estádio inicial de desenvolvimento de plântulas e/ou germinação de sementes (ASHRAF; FOOLAD, 2005; PLAUT et al., 2013).

Vinculada a essa concepção, pode-se relacionar este resultado à ação da tiamina como fator regulador do metabolismo de carbono e de síntese de proteínas (KAYA et al., 2015), tendo em vista que essa vitamina atua como coenzima em diversas vias metabólicas e pode proteger contra o estresse oxidativo causado por elementos abióticos (GOYER, 2010; KAYA et al., 2015).

Com relação ao índice de velocidade de germinação (IVG), a representação gráfica demonstra que $87 \%$ das variações ocorridas em função das diferentes concentrações de tiamina são explicadas pelo ajuste do modelo de regressão de comportamento linear crescente (Figura 3). Esses resultados sugerem que o tratamento de sementes de arroz com tiamina foi capaz de reduzir os efeitos danosos do estresse salino sobre o vigor das sementes, cuja concentração de $150 \mathrm{mg} \mathrm{L}^{-1}$ possibilitou maior índice $(16,20)$, correspondendo a 1,82 vezes superior ao valor obtido pelo tratamento que não recebeu a aplicação da vitamina (controle). Maiores índices indicam que as sementes germinaram mais rapidamente e de maneira uniforme, sendo assim, consideradas mais vigorosas (DONATO et al., 2015). Sementes de alto vigor apresentam maior potencial de resistir a estresses ambientais, refletindo diretamente na uniformidade da emergência e no estande final de plantas (CARVALHO; NAKAGAWA, 2012).

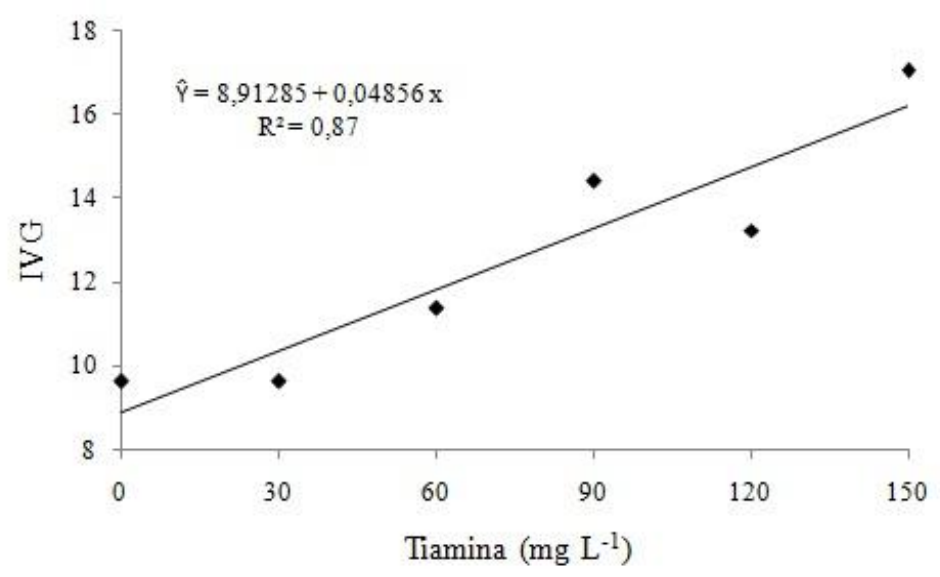

Figura 3. Índice de velocidade de germinação (IVG) de sementes de arroz submetidas ao estresse salino em função de concentrações de tiamina. Germination speed index (IVG) of rice seeds subjected to saline stress as a function of thiamine concentrations.

Fonte: Autoria própria. Own authorship.

Segundo Goyer (2010) e Kaya et al. (2015) a aplicação exógena de tiamina proporciona maior produção de metabólitos secundários responsáveis pela proteção dos tecidos vegetais através da ação antioxidante. Pode melhorar as condições fisiológicas, propiciando incremento das reservas energéticas e também nutricionais, essencial no correto desenvolvimento dos órgãos vegetais (BARAKAT, 2003). Esse fato reforça, ainda mais, que quando a planta se encontra sob estresse, a mesma pode utilizar as reservas para manutenção dos seus tecidos vegetais, proporcionando energia e contribuindo para manutenção do seu desenvolvimento (TAIZ et al., 2017). 
Para o comprimento de plântulas (Figura 4), observou-se comportamento linear crescente diretamente proporcional ao aumento das concentrações de tiamina, apresentando o máximo crescimento $(8,2 \mathrm{~cm})$ na concentração de $150 \mathrm{mg} \mathrm{L}^{-1}$, representando um incremento de $39,2 \%$ em relação ao tratamento controle (sem tiamina). A representação gráfica indica, portanto, a tendência de elevação de $0,01 \mathrm{~cm}$ no comprimento das plântulas sob estresse salino para cada miligrama de tiamina aplicada. Tais resultados sugerem que a aplicação da tiamina tenha refletido no vigor das sementes de arroz, expresso no desenvolvimento das plântulas.

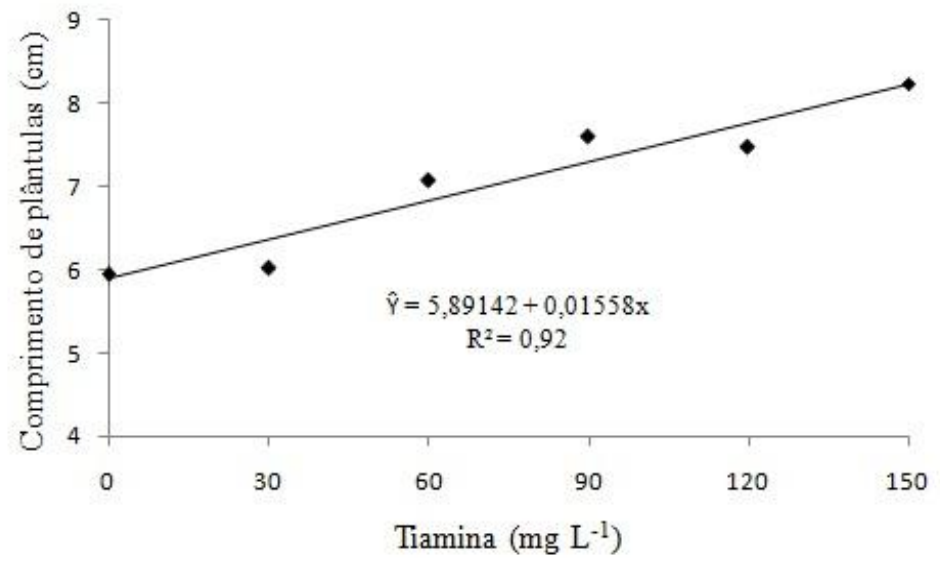

Figura 4. Comprimento de plântulas oriundas de sementes de arroz submetidas ao estresse salino em função de concentrações de tiamina. Seedling length from rice seeds subjected to salt stress as a function of thiamine concentrations.

Fonte: Autoria própria. Own authorship.

Possivelmente, devido ao fato das sementes mais vigorosas originarem plântulas com maior taxa de crescimento, em função da maior translocação das reservas dos tecidos de armazenamento para o crescimento do eixo embrionário (DAN et al., 1987). Esse efeito evidencia a capacidade de suportar condições de estresse salino, em função da utilização da tiamina, a qual possibilitou que as sementes germinassem e originassem plântulas maiores.

A vitamina atua no alongamento celular, no acúmulo de reservas e, consequentemente no crescimento vegetativo, mesmo em condições adversas impostas, por exemplo, pela salinidade (ABDELHAMID et al., 2013). Para El-Bassiouny et al. (2014) a aplicação de vitamina na cultura do trigo sob estresse hídrico, efetivamente a nicotinamida na concentração de $5 \mathrm{mg} \mathrm{L}^{-1}$, via imersão de sementes, causou incrementos a todos os critérios morfológicos, metabólicos, minerais e no rendimento, com efeito no crescimento da produtividade.

Observa-se resultados alinhados com Abdallah et al. (2016) que atribuiu aumento no crescimento e ganho de massa das plantas mediante a aplicação de vitamina, através da aplicação foliar de solução de $100 \mathrm{mg} \mathrm{L}^{-1}$ de nicotinamida na cultura da quinoa.

A massa seca de plântulas não apresentou diferença significativa $(\mathrm{P}>0,05)$ entre as concentrações de tiamina utilizadas, com valor médio de 13,83 mg plântula-1 (Figura 5). Vendruscolo et al. (2018) avaliando o tratamento de sementes de feijão com tiamina, também observaram que a aplicação de tiamina não apresentou diferença significativa para massa seca de parte aérea. 


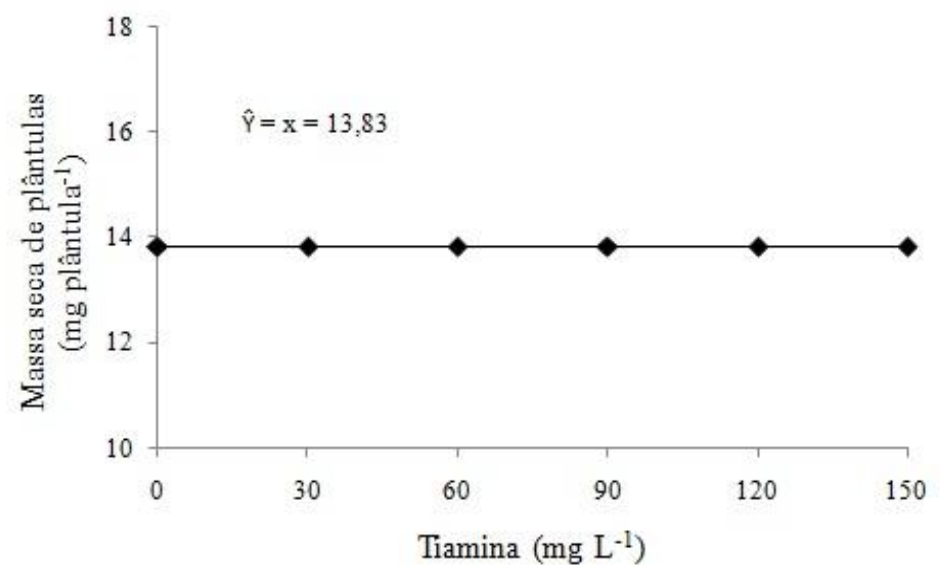

Figura 5. Massa seca de plântulas oriundas de sementes de arroz submetidas ao estresse salino em função de concentrações de tiamina. Seedling dry mass from rice seeds subjected to saline stress as a function of thiamine concentrations.

Fonte: Autoria própria. Own authorship.

Tendo em vista os resultados obtidos, pode-se inferir que a aplicação exógena de tiamina é uma opção para amenizar os efeitos do estresse, no entanto, vale ressaltar que o modo de aplicação, a concentração e a época de aplicação podem influenciar nos resultados. Vendruscolo et al. (2020) observaram que a concentração de $100 \mathrm{mg} \mathrm{L}^{-1}$, aplicada aos 30 dias após emergência, foi eficiente em reduzir os efeitos do déficit hídrico em plantas de arroz. Pode-se inferir, inclusive, que a diferença nas concentrações efetivas se deve ao intervalo de tempo ou a forma de aplicação. Sayed e Gadallah (2002) administraram a concentração de 5 ou $10 \mathrm{mg} \mathrm{L}$ ${ }^{1}$ de tiamina, com aplicação foliar a cada dois dias. Kaya et al. (2015) observaram que tanto a embebição das sementes quanto a aplicação foliar de 100 ou $125 \mathrm{mg} \mathrm{L}^{-1}$ de tiamina melhorou o crescimento de plantas de milho em condições salinas. No presente estudo, a concentração com melhores resultados foi a de $150 \mathrm{mg} \mathrm{L}^{-1}$, sendo que o uso de concentrações menores (90 e $120 \mathrm{mg} \mathrm{L}^{-1}$ ) também apresentaram bons resultados quando comparadas com a testemunha. Desse modo, salienta-se que a tiamina está emergindo como uma molécula importante para a resistência e adaptação das culturas sob estresse biótico e abiótico, o que impacta diretamente no estabelecimento das plantas.

\section{CONCLUSÃO}

A Tiamina exibe atividade promissora nos atributos fisiológicos e no mecanismo de defesa contra o estresse nas plantas. Sementes de arroz tratadas na concentração de $150 \mathrm{mg} \mathrm{L}^{-1}$ de tiamina expressam melhores respostas na germinação e no desenvolvimento inicial de plântulas de arroz em condições de estresse salino.

\section{AGRADECIMENTOS}

O presente trabalho foi realizado com apoio da Coordenação de Aperfeiçoamento de Pessoal de Nível Superior - Brasil (CAPES) - Código de Financiamento 001. Agradecemos também à Fundação de Amparo a Pesquisa do Estado de Minas Gerais (FAPEMIG), ao 
Conselho Nacional de Desenvolvimento Científico e Tecnológico (CNPq), pelo apoio financeiro e concessão de bolsas de estudo.

\section{REFERÊNCIAS BIBLIOGRÁFICAS}

ABDALLAH, M. M. S.; EL HABBASHA, S. F.; EL SEBAI, T. Comparison of yeast extract and Nicotinaminde foliar applications effect on quinoa plants grown under sandy soil condition.

International Journal of Pharm Tech Research, Mumbai, v. 9, n. 7, p.24-32, 2016. Disponível

em: https://www.researchgate.net/publication/307016945_Comparison_of_yeast_extract_and_nic otinaminde_foliar_applications_effect_on_quinoa_plants_grown_under_sandy_soil_condition . Acesso em: 10 ago. 2019.

ABDELHAMID, M. T.; SADAK, M. S. H.; SCHMIDHALTER, U. R. S.; EL-SAADY, A-K. Efectos combinados del estrés por salinidad y la nicotinamida sobre parámetros bioquímicos y fisiológicos en plantas de haba. Acta Biologica Colombiana, Bogotá, v. 18, n. 3, p.499-509, 2013.

Disponível

em: https://revistas.unal.edu.co/index.php/actabiol/article/view/38953/43334. Acesso em: 05 set. 2019.

ASHRAF, M.; FOOLAD, M. R. Pre-sowing seed treatment-a shotgun approach to improve germination, plant growth, and crop yield under saline and non-saline conditions. Advances in Agronomy, San Diego, v. 88, p.223-271, 2005. Disponível em: https://pennstate.pure.elsevier.com/en/publications/pre-sowing-seed-treatment-a-shotgunapproach-to-improve-germinati. Acesso em: 17 set. 2019.

BARAKAT, $\mathrm{H}$. Interactive effects of salinity and certain vitamins on gene expression and cell division. International Journal of Agriculture \& Biology, Pakistan, v. 5, n. 3, p.219-225, 2003.

Disponível

em:

https://www.researchgate.net/publication/252890280_Interactive_Effects_of_Salinity_and_C ertain_Vitamins_on_Gene_Expression_and_Cell_Division. Acesso em: 03 out. 2019.

BENITEZ, L. C.; RODRIGUES, I. C. S.; ARGE, L. W. P.; RIBEIRO, M. V.; BRAGA, E. J. B. Análise multivariada da divergência genética de genótipos de arroz sob estresse salino durante a fase vegetativa. Revista Ciência Agronômica, Fortaleza, v. 42, n. 2, p.409-416, 2011. Disponível em: http://ccarevista.ufc.br/seer/index.php/ccarevista/article/view/1744. Acesso em: 09 out. 2019.

BOUBAKRI, H.; WAHAB, M. A.; CHONG, J.; BERTSCH, C.; MLIKI, A.; SOUSTREGACOUGNOLLE, I. Thiamine induced resistance to Plasmopara viticola in grapevine and elicited host-defense responses, including HR like-cell death. Plant Physiology and Biochemistry, Amsterdam, v. 57, n. 1, p.120-133, 2012. Disponível em: https://www.ncbi.nlm.nih.gov/pubmed/22698755. Acesso em: 05 out. 2019.

BRASIL. Ministério da Agricultura, Pecuária e Abastecimento. Secretaria de Defesa Agropecuária. Regras para análise de sementes. Brasília: Mapa/ACS, 2009. 399 p. 
Disponível em: http://www.agricultura.gov.br/assuntos/insumos-agropecuarios/arquivospublicacoes-insumos/2946_regras_analise_sementes.pdf. Acesso em: 10 out. 2019.

BRASIL. Ministério da Agricultura, Pecuária e Abastecimento. Padrões para a produção e a comercialização de sementes de arroz (Oryza sativa L.). Instrução normativa ${ }^{\circ} 9$, de 2 de junho de 2005. Diário Oficial da União, Brasília, DF, 17 set. 2013, Seção 1, p. 3.

CARVALHO, N. M.; NAKAGAWA, J. Sementes: ciência, tecnologia e produção. 5. ed. Jaboticabal: FUNEP, 2012. 590 p.

DAN, E. L.; MELLO, V. D. C.; WETZEL, C. T.; POPINIGIS, F.; ZONTA, E. P. Transferência de matéria seca como método de avaliação do vigor de sementes de soja. Revista Brasileira de Sementes, Brasília, v. 9, n. 3, p.45-55, 1987. Disponível em: http://www.scielo.br/pdf/rbs/v29n2/v29n2a12.pdf. Acesso em: 06 nov. 2019.

DONATO, L. M. S.; RABELO, M. M.; DAVID, A. M. S. S.; ROCHA, A. F.; ROCHA, A. S.; BORGES, G. A. Qualidade fisiológica de sementes de melão em função do estádio de maturação dos frutos. Comunicata Scientiae, Bom Jesus, v. 6, n. 1, p.49-56, 2015. Disponível em: https://comunicatascientiae.com.br/comunicata/article/view/544/302. Acesso em: $11 \mathrm{mar}$ 2021.

EL-BASSIOUNY, H. S. M.; BAKRY, A. B.; ATTIA, A. A. E. M.; AllaH, M. M.A. Physiological role of humic acid and nicotinamide on improving plant growth, yield, and mineral nutrient of wheat (Triticum durum) grown under newly reclaimed sandy soil. Agricultural Sciences, v. 5, n. 8, p.687-700, 2014. Disponível em: https://www.researchgate.net/publication/269948535_Physiological_Role_of_Humic_Acid_a nd_Nicotinamide_on_Improving_Plant_Growth_Yield_and_Mineral_Nutrient_of_Wheat_Tri ticum_durum_Grown_under_Newly_Reclaimed_Sandy_Soil. Acesso em: 08 out. 2019.

EZZAT, S. E. Effect of thiamine and biotin vitamins on growth and yield of smooth wheat Triticum aestivum L. Annals of the Romanian Society for Cell Biology, v. 25, n. 5, p.53055313, 2021. Disponível em: https://www.annalsofrscb.ro/index.php/journal/article/view/6393/4854. Acesso em: 05 ago. 2021.

FERREIRA, D. F. Sisvar: a computer statistical analysis system. Ciência e Agrotecnologia, Lavras, v. 35, n. 6, p.1039-1042, 2011. Disponível em: http://www.scielo.br/scielo.php?script=sci_arttext\&pid=S1413-70542011000600001. Acesso em: 06 out. 2019.

GOYER, A. Thiamine in plants: aspects of its metabolism and functions. Phytochemistry, Amsterdam, v. 71, n. 14, p.1615-1624, 2010. Disponível em: https://www.ncbi.nlm.nih.gov/pubmed/20655074. Acesso em: 20 de out. 2019.

KHAN, M. H.; PANDA, S. K. Alterations in root lipid peroxidation and antioxidative responses in two rice cultivars under NaCl-salinity stress. Acta Physiologiae Plantarum, Heidelberg, v. 30, n. 1, p.81-89, 2008. Disponível em: https://link.springer.com/article/10.1007/s11738-0070093-7. Acesso em: 22 out. 2019. 
KAYA, C.; ASHRAF, M.; SONMEZ, O.; TUNA, A. L.; POLAT, T.; AYDEMIR, A. Exogenous application of thiamin promotes growth and antioxidative defense system at anitial phase sof development in salt-stressed plants of two maize cultivars differing in salinity tolerance. Acta Physiologiae Plantarum, Heidelberg, v. 37, n. 1741, p.1-12, 2015. Disponível em:

https://www.researchgate.net/publication/273328825_Exogenous_application_of_thiamin_pr omotes_growth_and_antioxidative_defense_system_at_initial_phases_of_development_in_sa lt-stressed_plants_of_t. Acesso em: 25 out. 2019.

LARRÉ, C. F.; MORAIS, D. M.; LOPES, N. F. Qualidade fisiológica de sementes de arroz tratadas com solução salina e 24-epibrassinolídeo. Revista Brasileira de Sementes, Londrina, v. 33, $\quad$ n. $1, \quad$ p.86-94, 2011. Disponível em: http://www.scielo.br/scielo.php?pid=S010131222011000100010\&script=sci_abstract\&tlng=p t. Acesso em: 28 out. 2019.

LIMA, M. G. S.; LOPES, N. F.; BACARIN, M. A.; MENDES. C. R. Efeito do estresse salino sobre a concentração de pigmentos e prolina em folhas de arroz. Bragantia, Campinas, v. 63, n. 3, p.335-340, 2004. Disponível em: http://www.scielo.br/scielo.php?script=sci_abstract\&pid=S0006-

$87052004000300003 \& \operatorname{lng}=\mathrm{en} \& n r m=i s o \& t \operatorname{lng}=$ pt. Acesso em: 29 set. 2019.

MAGUIRE, J. A. Speed of germination: aid in selection an evaluation for seedling emergence and vigor. Crop Science, Madison, v. 2, n. 2, p.176-177, 1962. Disponível em: https://acsess.onlinelibrary.wiley.com/doi/abs/10.2135/cropsci1962.0011183X000200020033 x. Acesso em: 15 out. 2019.

MARCOS FILHO, J. Fisiologia de sementes de plantas cultivadas. 2.ed. Piracicaba: FEALQ, 2015. $660 \mathrm{p}$.

NEUMANN, G.; AZAIZEH, H. A.; MARSCHNER, H. Thiamine (vitamin B1) seed treatment enhances germination and seedling growth of bean (Phaseolus vulgaris L.) exposed to soaking injury. Journal of Plant Nutrition and Soil Science, v. 159, n. 5, p.491-498, 1996. Disponível em: https://onlinelibrary.wiley.com/doi/epdf/10.1002/jpln.1996.3581590512. Acesso em: 10 mar. 2021.

PLAUT, Z.; EDELSTEIN, M.; BEN-HUR, M. Overcoming salinity barriers to crop production using traditional methods. Critical Reviews in Plant Sciences, New York, v. 32, n. 4, p.250291, 2013. Disponível em: https://www.researchgate.net/publication/263416288_Overcoming_Salinity_Barriers_to_Cro p_Production_Using_Traditional_Methods. Acesso em: 10 out. 2019.

SAYED, S. A.; GADALLAH, M. A. A. Effects of shoot and root application of thiamin on thiamin on salt-stressed sunflower plants. Plant Growth Regulation, v. 36, n. 1, p.71-80, 2002. Disponível em: https://link.springer.com/article/10.1023/A:1014784831387. Acesso em: 10 mar. 2021.

TAIZ, L.; ZEIGER, E.; MOLLER, I.; MURPHY, A. Fisiologia e desenvolvimento vegetal. 6.ed. Porto Alegre: Artmed, 2017. 888 p. 
TUNA, A. L.; KAYA, C.; ALTUNLU, H.; ASHRAF, M. Mitigation effects of non-enzymatic antioxidants in maize (Zea mays L.) plants under salinity stress. Australian Journal of Crop Science, Lismore, v. 7, n. 8, p.1181-1188, 2013. Disponível em: https://www.researchgate.net/publication/286291128_Mitigation_effects_of_nonenzymatic_antioxidants_in_maize_Zea_mays_L_Plants_under_salinity_stress. Acesso em: 15 out. 2019.

TUNC-OZDEMIR, M.; MILLER, G.; SONG, L.; KIM, J.; SODEK, A.;KOUSSEVITZKY,S.; MISRA, A. N.; MITTLER, R.; SHINTANI, D. Thiamin confers enhanced tolerance to oxidative stress in Arabidopsis. Plant Physiology, Washington, v. 151, n. 1, p.421-432, 2009. Disponível em: http://www.plantphysiol.org/content/151/1/421. Acesso em: 20 out. 2019.

VENDRUSCOLO, E. P.; RODRIGUES, A. H. A.; MARTINS, A. P. B.; CAMPOS, L. F. C.; SELEGUINI, A. Tratamento de sementes com niacina ou tiamina promove o desenvolvimento e a produtividade do feijoeiro. Revista de Ciências Agroveterinárias, Lages, v. 17, n. 1, p.8390, 2018. Disponível em: http://revistas.udesc.br/index.php/agroveterinaria/article/view/9544/0. Acesso em: 28 out. 2019.

VENDRUSCOLO, E. P.; RODRIGUES, A. H. A.; OlIVEIRA, P. R.; LEITÃO, R. A.; CAMPOS, L. F. C.; SELEGUINI, A.; LIMA, S. F. Aplicação exógena de tiamina em arroz de terras altas submetido ao déficit hídrico. Revista de Ciências Agroveterinárias, Lages, v. 19, n. $1, \quad$ p.48-53, 2020. Disponível em: https://www.readcube.com/articles/10.5965\%2F223811711912020048. Acesso em: 10 mar. 2021. 